\title{
Ventricular Microaneurysms in Moyamoya Angiopathy Visualized with 7T MR Angiography
}

\author{
(D)T. Matsushige, (D) M. Kraemer, (D) M. Schlamann, (D). Berlit, (D). Forsting, (D) M.E. Ladd, (D). Sure, and (D).H. Wrede
}

\begin{abstract}
SUMMARY: The pathophysiologic role of hemodynamic alteration to peripheral vessels in Moyamoya angiopathy and the formation of microaneurysms remains unclear. The purpose of this study was to investigate microaneurysms in collateral Moyamoya vessels by using 7T ultra-high-field MR imaging. Ten patients with Moyamoya disease were evaluated with TOF-MRA at 7T acquired with $0.22 \times 0.22 \times 0.41$ $\mathrm{mm}^{3}$ resolution. In 10 patients, 4 microaneuryms located in the ventricles were delineated. The mean diameters of collateral vessels and microaneurysms arising from those vessels were $0.87 \mathrm{~mm}$ (range, $0.79-1.07 \mathrm{~mm}$ ) and $0.80 \mathrm{~mm}$ (range, $0.56-0.96 \mathrm{~mm}$ ), respectively. In 1 case with follow-up scans 6 months after a direct extracranial-intracranial bypass operation, the microaneurysm disappeared. Ventricular microaneurysms in Moyamoya angiopathy collateral vessels, inaccessible by conventional imaging techniques, can be detected by 7T TOF-MRA.
\end{abstract}

ABBREVIATION: MMA = Moyamoya angiopathy

M oyamoya angiopathy (MMA) is a rare cerebrovascular pathology characterized by progressive occlusion of the terminal carotid arteries associated with the formation of collateral Moyamoya vessels. ${ }^{1,2}$ The patients could have ischemic and/or hemorrhagic stroke, though there are notable differences in clinical symptoms among the age of onset and race. ${ }^{3-6}$ The proposed pathophysiologic mechanism for hemorrhage in MMA is longterm hemodynamic stress to collateral vessels. ${ }^{5-8}$ It has been hypothesized that formation of microaneurysms might be an additional pathophysiologic explanation. Small aneurysms $(2-3 \mathrm{~mm})$ of these collateral vessels have been associated with intraventricular hemorrhage in several reports. ${ }^{7-11}$ However, the incidence and natural history of microaneurysms associated with MMA remain unclear because detection of submillimeter-range aneu-

Received December 18, 2015; accepted after revision February 5, 2016.

From the Departments of Neurosurgery (T.M., U.S., K.H.W.) and Diagnostic and Interventional Radiology and Neuroradiology (M.S., M.F.), University Hospital Essen, University Duisburg-Essen, Essen, Germany; Department of Neurosurgery (T.M.), Graduate School of Biomedical and Health Sciences, Hiroshima University, Hiroshima, Japan; Erwin L. Hahn Institute for Magnetic Resonance Imaging (T.M., M.E.L. K.H.W.), University Duisburg-Essen, Essen, Germany; Department of Neurology (M.K., P.B.), Alfried Krupp Hospital, Essen, Germany; Department of Neuroradiology (M.S.), University Hospital Giessen, Giessen, Germany; and Division of Medical Physics in Radiology (M.E.L.), German Cancer Research Center, Heidelberg, Germany. T. Matsushige and M. Kraemer contributed equally to this work.

Karsten H. Wrede was supported by the University Duisburg-Essen (IFORES grant: Programm zur internen Forschungsförderung Essen).

Please address correspondence to Toshinori Matsushige, MD, University Hospital Essen, Department of Neurosurgery, Hufelandstr 55, 45147 Essen, Germany; e-mail: Toshinori.Matsushige@uk-essen.de, karsten.wrede@uk-essen.de

http://dx.doi.org/10.3174/ajnr.A4786 rysms remains unfeasible with conventional imaging techniques. This study aimed to investigate underlying microaneurysms of collateral vessels by using ultra-high-field 7T TOF-MRA.

\section{MATERIALS AND METHODS}

In addition to a standard clinical work-up with 3T TOF-MRA and selective DSA, patients with MMA were prospectively recruited in a 7T TOF-MRA feasibility study between October 2011 and November $2012 .^{12}$ These data were recently re-evaluated to screen for the presence of microaneurysms in collateral Moyamoya vessels. The study was conducted according to the principles expressed in the Declaration of Helsinki and was approved by the University Duisburg-Essen institutional review board. Written informed consent was obtained before each examination. All 7T examinations were performed by using a whole-body MR imaging system (Magnetom 7T; Siemens, Erlangen, Germany) equipped with a 1-channel transmit/32-channel receive head radiofrequency coil (Nova Medical, Wilmington, Massachusetts). The system has a gradient system providing $45 \mathrm{mT} / \mathrm{m}$ maximum amplitude and a slew rate of $200 \mathrm{mT} / \mathrm{m} / \mathrm{ms}$. For MRA, a previously described customized 3D fast low-angle shot TOF pulse sequence was applied. ${ }^{12,13}$ Datasets were acquired with the following parameters: flip angle $\alpha=18^{\circ}, \mathrm{TE}=4.34 \mathrm{~ms}$, TR $=20 \mathrm{~ms}$, FOV $=200 \times 169 \times 46 \mathrm{~mm}^{3}, 112$ sections per slab (oversampling $14 \%$ ), parallel imaging (generalized autocalibrating partially parallel acquisition) with an acceleration factor $\mathrm{R}=4$ (phase direction), partial Fourier 6/8 in both section and phase directions, matrix $=896 \times 756$ (noninterpolated), voxel size $=0.22 \times$ 
Patient demographics and anatomic characteristics for all microaneurysms

\begin{tabular}{|c|c|c|c|c|c|c|c|c|c|}
\hline Pt No. & No. & Age (yr) & Sex & $\begin{array}{l}\text { Bypass } \\
\text { Surgery }\end{array}$ & $\begin{array}{c}\text { Collateral } \\
\text { Vessels }\end{array}$ & Microaneurysm & Location & $\begin{array}{c}\text { Maximum } \\
\text { Diameter }(\mathrm{mm})\end{array}$ & $\begin{array}{c}\text { Diameter of a } \\
\text { Ventricular Collateral } \\
\text { Vessel (mm) }\end{array}$ \\
\hline \multirow[t]{2}{*}{1} & 1 & 23 & $M$ & Pre & + & - & & & \\
\hline & 2 & 24 & & Post & + & - & & & \\
\hline 2 & 3 & 46 & $M$ & Post & + & - & & & \\
\hline 3 & 4 & 26 & $\mathrm{~F}$ & Pre & - & - & & & \\
\hline 4 & 5 & 35 & $\mathrm{~F}$ & Pre & ++ & + & 3rd Vent. & 0.76 & 1.07 \\
\hline \multirow[t]{2}{*}{5} & 6 & 34 & $\mathrm{~F}$ & Pre & ++ & + & 3rd Vent. & 0.56 & 0.82 \\
\hline & 7 & 34 & & Post & ++ & Disappeared $^{\mathrm{a}}$ & Disappeared $^{\mathrm{a}}$ & & \\
\hline 6 & 8 & 29 & $\mathrm{~F}$ & Pre & + & + & Lateral Vent. & 0.96 & 0.79 \\
\hline 7 & 9 & 58 & $\mathrm{~F}$ & Post & + & - & & & \\
\hline 8 & 10 & 42 & $\mathrm{~F}$ & Post & + & + & Subependium & 0.93 & 0.81 \\
\hline 9 & 11 & 38 & $\mathrm{~F}$ & Pre & - & - & & & \\
\hline 10 & 12 & 35 & $\mathrm{~F}$ & Pre & + & - & & & \\
\hline
\end{tabular}

Note:-Pt indicates patient; Pre, before; Post, after; +, moderate development of collateral vessels in the ventricles; ++ , advanced development of collateral vessels in the ventricles, -, not delineated; Vent., ventricle.

a Disappeared after bypass surgery.
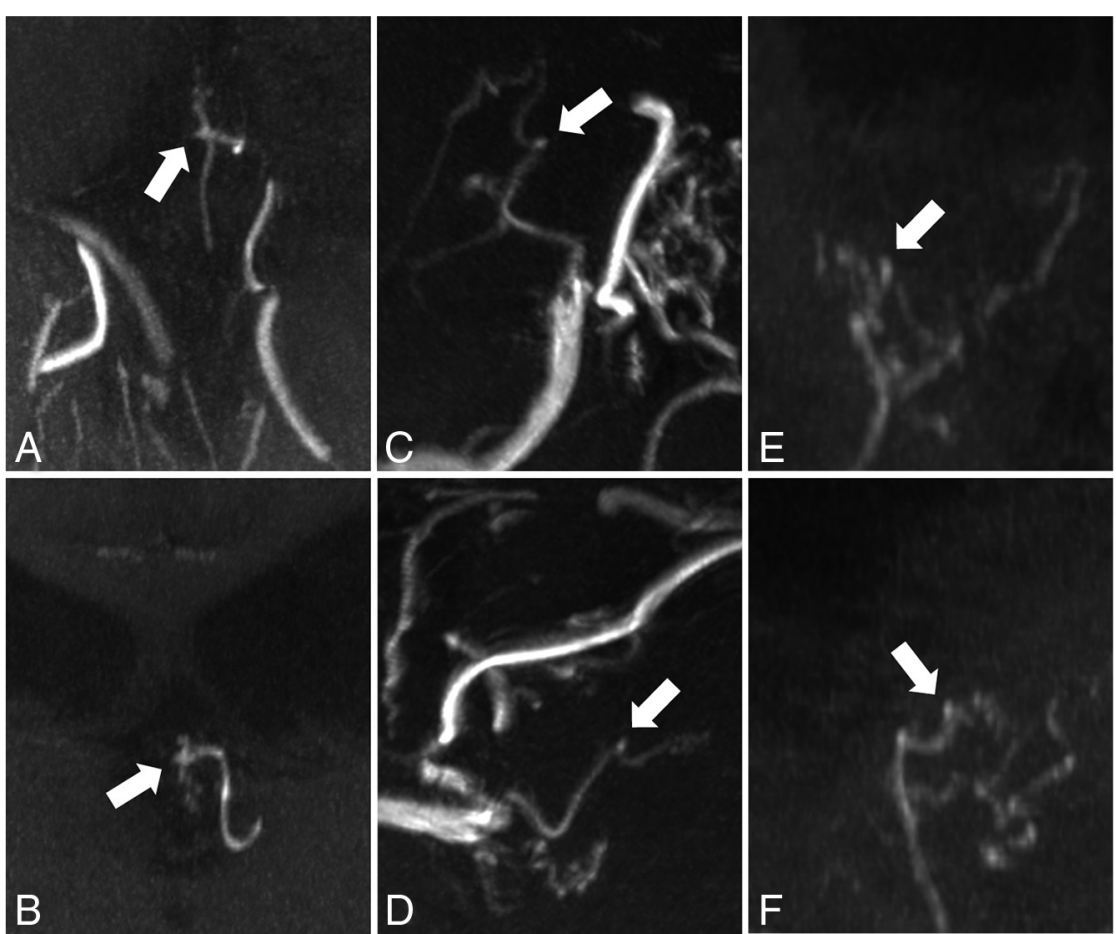

FIG 1. Two different projections of MIP from TOF-MRA at 7T in cases 4 ( $A$ and $B), 6$ ( $C$ and $D$ ), and $8(E$ and $F)$ demonstrate an intraventricular microaneurysm (arrow) arising from collateral vessels.

$0.22 \times 0.41 \mathrm{~mm}^{3}$ (noninterpolated), and total acquisition time of 6 minutes 22 seconds. Images were analyzed by 2 experienced vascular neurosurgeons (T.M. and K.H.W.) and an experienced neuroradiologist (M.S.) in a consensus reading by using an opensource medical image viewer (Horos; http://www.horosproject. org/) in a 3-step evaluation process. At first, every rater individually assessed the transverse source images for the presence of microaneurysms. In the second step, multiplanar 3D image reconstructions and MIPs were similarly evaluated. Finally, all 3 raters discussed their individual evaluations to establish a consensus reading.

\section{RESULTS}

Basic demographic data for all patients and major anatomic features of microaneurysms are summarized in the Table. There were no signs of acute hemorrhage or bleeding remnants in any patient. Collateral vessels in the ventricles branching from the posterior choroidal arteries were present in 8 of 10 patients. Neither conventional MRA nor DSA detected microaneurysms in these collateral Moyamoya vessels. All raters detected 3 microaneurysms in transverse source images during the initial evaluation (cases 5, 6, and 8). Two raters detected a microaneurysm in transverse source images (case 4), which was only suspected in these images by the third rater. All 4 microaneurysms were individually detected by the raters in multiplanar $3 \mathrm{D}$ image reconstructions and MIPs. After individual assessments, all findings were discussed to have a consensus reading. There was no false-positive or false-negative detection of a microaneurysm by a single rater. The mean diameters of collateral vessels and microaneurysms arising from those vessels were $0.87 \mathrm{~mm}$ (range, $0.79-1.07 \mathrm{~mm}$ ) and $0.80 \mathrm{~mm}$ (range, $0.56-0.96 \mathrm{~mm}$ ), respectively. Figure 1 illustrates specific features of 3 microaneurysms. One microaneurysm disappeared on the follow-up examination 6 months after the direct extracranial-intracranial bypass operation (Figs 2 and 3).

\section{DISCUSSION}

This is the first presentation of MMA with microaneurysms in collateral Moyamoya vessels. This study illustrates the possible clinical application of 7T TOF-MRA to detect submillimeterrange microaneurysms arising from peripheral collateral vessels in MMA. So far, only 1 histopathologic study has analyzed the presence of microaneurysms (200- to 550- $\mu \mathrm{m}$ diameter) in MMA. ${ }^{14}$ It revealed true microaneurysm formation or degenerative changes in the vessels predisposing to rupture of perforating 


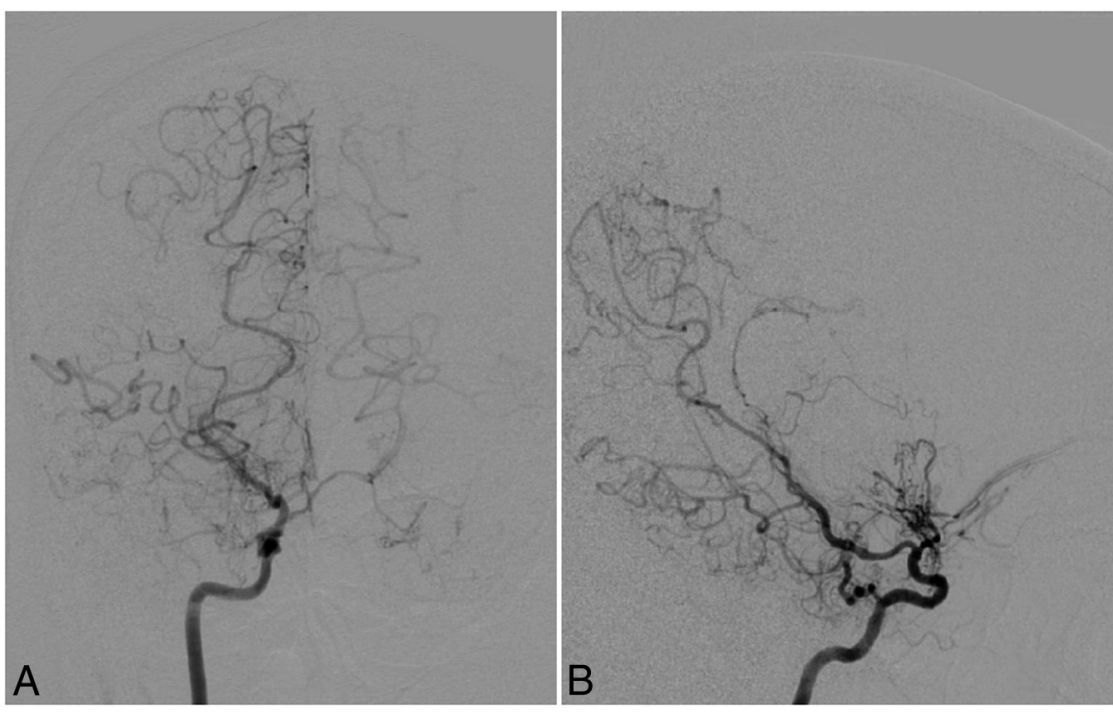

FIG 2. Cerebral angiography with anteroposterior $(A)$ and lateral $(B)$ views in case 5 . Right internal carotid angiography reveals occlusion of the right carotid fork and tiny basal collateral vessels. The right posterior cerebral artery and right posterior choroidal artery are also prominent as collateral vessels. No intracranial aneurysms can be delineated.
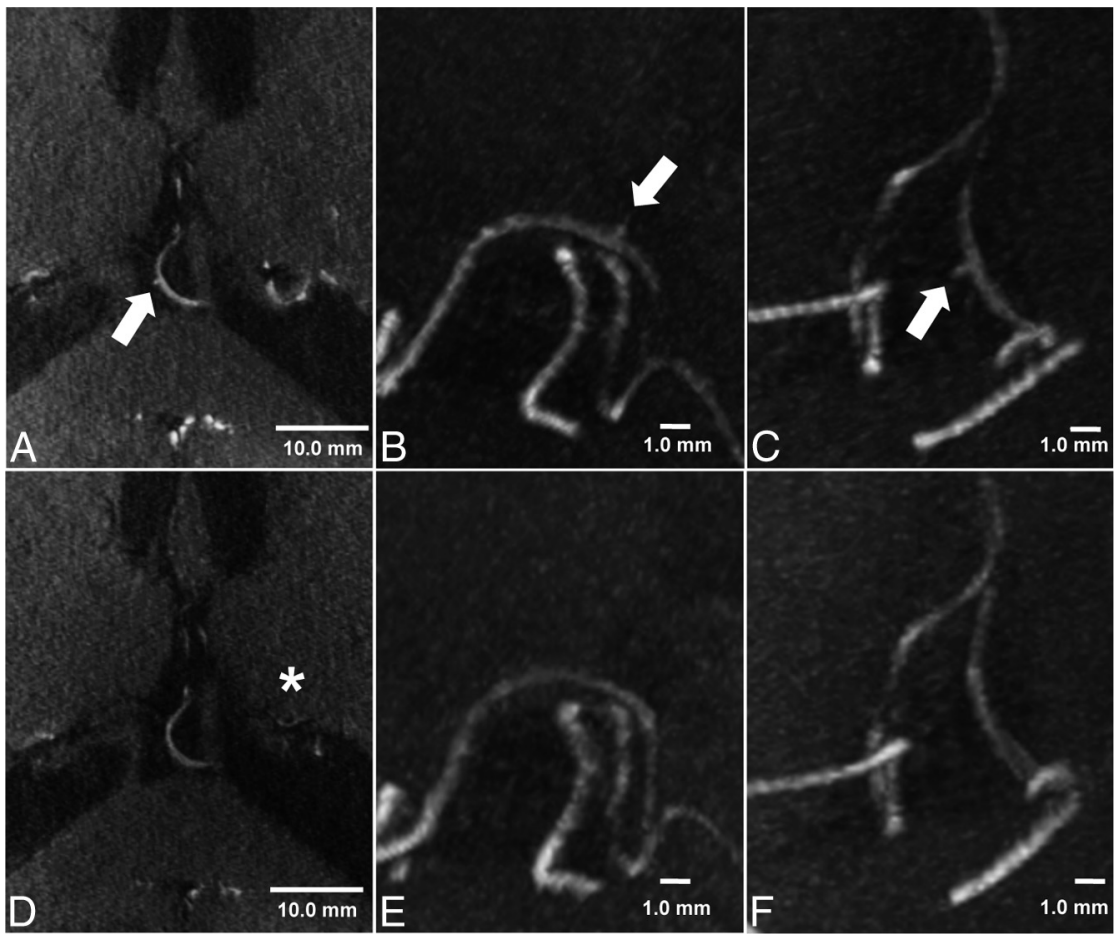

FIG 3. TOF-MRA and MIP of TOF-MRA at 7 T before $(A-C)$ and 6 months after $(D-F)$ the bypass operation in case 5 . A microaneurysm ( $560-\mu \mathrm{m}$ maximum diameter) is delineated arising from a collateral vessel of the posterior choroidal artery in the third ventricle (arrow). Six months after the bypass operation, MIP of TOF-MRA shows disappearance of the microaneurysm. The signal intensity of collateral vessels has decreased in the matched axial planes (asterisk). The scale bar indicates $10.0 \mathrm{~mm}$ (TOF-MRA, $A$ and $D$ ) and $1.0 \mathrm{~mm}$ (MIP image, $B$ and $C ; E$ and $F$ ), respectively.

arteries. However, the prevalence of these microaneurysms remains unclear because current imaging techniques are unable to detect them. Given the previously published histopathologic data, ${ }^{14}$ spatial resolution has to be well below the diameter of Moyamoya vessels to be capable of visualizing microaneuryms. Detecting these submillimeter-range microaneurysms in com- plex and tiny collateral Moyamoya vessels remains unfeasible even for DSA, the current criterion standard, or highresolution $3 \mathrm{~T}$ MRA. The high spatial resolution used in the presented study allowed visualizing these microaneuryms in vivo for the first time. Several recent studies showed the excellent diagnostic accuracy of this imaging technique to delineate microvascular structures and vessel walls. ${ }^{15-18}$

The formation of flow-related aneurysms has recently been investigated in patients with cerebral arteriovenous malformations. ${ }^{19}$ The proposed pathophysiologic mechanism involves hemodynamic alterations to peripheral vessel walls that cannot compensate for increased blood flow. ${ }^{19}$ The same pathophysiologic mechanism seems to play a key role in aneurysm formation in MMA and can explain intracranial hemorrhage in patients with Moyamoya disease. ${ }^{5-8}$ Nevertheless, dedicated computational flow simulations are pending to evaluate this hypothesis. Several authors suggested the relevance of hemodynamic changes for the treatment of flowrelated peripheral aneurysms. ${ }^{9-11}$ In their recent study, Miyamoto et $\mathrm{al}^{20}$ showed a significant reduction of intracranial hemorrhage after superficial temporal artery-MCA bypass surgery. They speculated that reduction of longterm hemodynamic alterations in fragile Moyamoya collateral vessels might explain their findings. The disappearance of 1 microaneurysm in the present case series (case 5) might support the hypothesis of favorable hemodynamic alterations after a bypass operation.

The prevalence of microaneurysms and their pathophysiologic relevance remains unclear. This report warrants further prospective studies to reveal the prevalence of microaneurysms associated with MMA and their fate after treatment.

\section{Limitations}

The lack of a diagnostic criterion standard for nonsurgical detection of microaneurysms is the main limitation of the present study. None of the patients underwent surgical exposure of parent vessels and microaneurysms. Thus, histopathologic validation of the microaneurysms was not available. However, the dedicated 3-step image assessment by 3 experienced raters and the high spatial resolution of the 
applied 7T TOF sequence yields reliable results. The high diagnostic accuracy to delineate microvascular structures has recently been shown for the applied TOF sequence.

The small number patients was another limitation to the study. However, enlisting a substantially larger number of patients with MMA for a 7T MR imaging study remains restricted due the low incidence of MMA and the limited availability of 7T MR imaging systems.

\section{CONCLUSIONS}

Ventricular microaneurysms in MMA collateral vessels, inaccessible by conventional imaging techniques, can be detected by $7 \mathrm{~T}$ TOF-MRA.

Disclosures: Markus Kraemer-UNRELATED: Grants/Grants Pending: Novartis grant, grant from German Neurology Society; Payment for Lectures (including service on Speakers Bureaus): Teva, Novartis, Merck Serono, Shire; Travel/Accommodations/ Meeting Expenses Unrelated to Activities Listed: Teva, Biogen, Novartis. Peter Berlit-UNRELATED: Payment for Lectures (including service on Speakers Bureaus): Merck, Sharp \& Dohme GmbH, Bayer HealthCare Pharmaceuticals, Novartis. Karsten $\mathrm{H}$. Wrede—RELATED: Grant: IFORES (Programm zur internen Forschungsförderung Essen, University Duisburg-Essen).

\section{REFERENCES}

1. Suzuki J, Takaku A. Cerebrovascular "moyamoya" disease: disease showing abnormal net-like vessels in base of brain. Arch Neurol 1969;20:288-99 CrossRef Medline

2. Research Committee on the Pathology and Treatment of Spontaneous Occlusion of the Circle of Willis; Health Labour Sciences Research Grant for Research on Measures for Infractable Diseases. Guidelines for diagnosis and treatment of moyamoya disease (spontaneous occlusion of the circle of Willis). Neurol Med Chir (Tokyo) 2012;52:245-66 CrossRef Medline

3. Hallemeier CL, Rich KM, Grubb RL Jr, et al. Clinical features and outcome in North American adults with moyamoya phenomenon. Stroke 2006;37:1490-96 CrossRef Medline

4. Kraemer M, Heienbrok W, Berlit P. Moyamoya disease in Europeans. Stroke 2008;39:3193-200 CrossRef Medline

5. Kuroda S, Houkin K. Moyamoya disease: current concepts and future perspectives. Lancet Neurol 2008;7:1056-66 CrossRef Medline

6. Takahashi JC, Miyamoto S. Moyamoya disease: recent progress and outlook. Neurol Med Chir (Tokyo) 2010;50:824-32 CrossRef Medline

7. Kawaguchi S, Sakaki T, Morimoto T, et al. Characteristics of intra- cranial aneurysms associated with moyamoya disease: a review of 111 cases. Acta Neurochir 1996;138:1287-94 CrossRef Medline

8. Kobayashi E, Saeki N, Oishi H, et al. Long-term natural history of hemorrhagic moyamoya disease in 42 patients. J Neurosurg 2000;93: 976-80 CrossRef Medline

9. Adams HP Jr, Kassell NF, Wisoff HS, et al. Intracranial saccular aneurysm and moyamoya disease. Stroke 1979;10:174-79 CrossRef Medline

10. Kuroda S, Houkin K, Kamiyama H, et al. Effects of surgical revascularization on peripheral artery aneurysms in moyamoya disease: report of three cases. Neurosurgery 2001;49:463-67; discussion 67-68 CrossRef Medline

11. Ni W, Xu F, Xu B, et al. Disappearance of aneurysms associated with moyamoya disease after STA-MCA anastomosis with encephaloduro myosynangiosis. J Clin Neurosci 2012;19:485-87 CrossRef Medline

12. Wrede KH, Johst S, Dammann P, et al. Improved cerebral time-offlight magnetic resonance angiography at 7 Tesla: feasibility study and preliminary results using optimized venous saturation pulses. PLoS One 2014;9:e106697 CrossRef Medline

13. Johst S, Wrede KH, Ladd ME, et al. Time-of-flight magnetic resonance angiography at $7 \mathrm{~T}$ using venous saturation pulses with reduced flip angles. Invest Radiol 2012;47:445-50 CrossRef Medline

14. Yamashita M, Oka K, Tanaka K. Histopathology of the brain vascular network in moyamoya disease. Stroke 1983;14:50-58 CrossRef Medline

15. Conijn MM, Geerlings MI, Biessels GJ, et al. Cerebral microbleeds on MR imaging: comparison between 1.5 and 7T. AJNR Am J Neuroradiol 2011;32:1043-49 CrossRef Medline

16. van der Kolk AG, Zwanenburg JJ, Denswil NP, et al. Imaging the intracranial atherosclerotic vessel wall using 7T MRI: initial comparison with histopathology. AJNR Am J Neuroradiol 2015;36:694701 CrossRef Medline

17. Matsushige T, Chen B, Ringelstein A, et al. Giant intracranial aneurysms at 7T MRI. AJNR Am J Neuroradiol 2015 Nov 12. [Epub ahead of print] Medline

18. Matsushige T, Chen B, Dammann P, et al. Microanatomy of the subcallosal artery: an in-vivo $7 \mathrm{~T}$ magnetic resonance angiography study. Eur Radiol 2015 Nov 24. [Epub ahead of print] Medline

19. Shakur SF, Amin-Hanjani S, Mostafa H, et al. Hemodynamic characteristics of cerebral arteriovenous malformation feeder vessels with and without aneurysms. Stroke 2015;46:1997-99 CrossRef Medline

20. Miyamoto S, Yoshimoto T, Hashimoto N, et al; JAM Trial Investigators. Effects of extracranial-intracranial bypass for patients with hemorrhagic moyamoya disease: results of the Japan Adult Moyamoya Trial. Stroke 2014;45:1415-21 CrossRef Medline 